\title{
Особенности социально-психологической адаптации у лиц с разными стратегиями совладающего поведения
}

\author{
Анна А. Безуглова, Ольга С. Васильева, Лида Р. Правдина* \\ Южный федеральный университет, г. Ростов-на-Дону, Российская Федерация \\ *E-mail: Iprlis7@gmail.com
}

\begin{abstract}
Аннотация
Введение. Авторы показывают необходимость исследования системных характеристик Аичности, позволяющих ей быть эфорективной и работоспособной - социально-психологической адаптации и стратегий поведения; описывают сущность и предназначение совлалания как способа эфорективной алаптации человека к требованиям ситуации. Новизна исследования заключается в том, что впервые выраженность социально-психологической алаптации сравнивается А^я групп с разными индексами конструктивности повеАения.
\end{abstract}

Методы. Аля изучения особенностей адаптации у миц с разной выраженностью стратегий совлаАания применялись: метолика социально-психологической аАаптации К. Роджерса и Р. АаймонАа, метолика «Анкета оценки нервно-психической устойчивости "Прогноз-2"» В.Ю. Рыбникова; метолика «Шка^а SACS C. Хоборол^а» в адаптации Н.Е. Водопьяновой и Е.С. Старченковой.

Результаты. На выборке (51 человек - сотрудники производственного предприятия) последовательно был проведен анализ различий в группах, вылеленных по величине индекса конструктивности. Основные результаты: показаны отсутствие в выборке респонАентов с высокой устойчивостью, преоблалание среАи женщин Аиц с высокой конструктивностью поведения, а среди мужчин - С низкой. Показана связь высокой конструктивности повеАения с более высоким уровнем аАаптации и высокой нервно-психической устойчивостью. ВыАелен фактор ресурсов психологического зАоровья, в который вошли: инАекс конструктивности повеАения, аАаптация и алаптивность, принятие Аругих и стрессоустойчивость.

ОбсужАение результатов. В части взаимосвязи аАаптации со стрессоустойчивостью и конструктивными стратегиями поведения результаты полтвержАают исследования Аругих авторов. Вылеление фрактора ресурсов психологического зАоровья Аемонстрирует статистическую обусловленность взаимосвязи позитивных факторов психологического зАоровья. Описанный авторами относительно общий низкий уровень адаптации и нервно-психической устойчивости, а также конструктивности повеАения у трудоустроенных АюАей, Аает основание преАполагать детерминацию социально-психологической алаптивности не только 


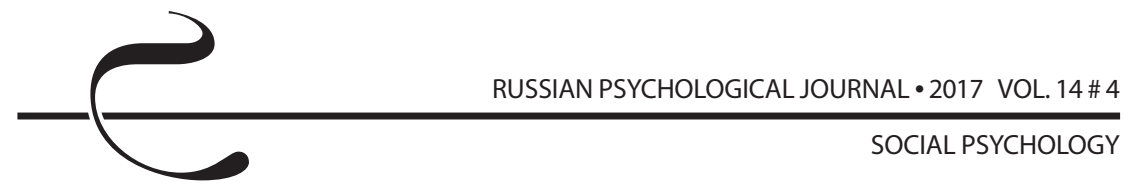

переживаниями удовлетворенности жизнью, трудом, семейными отношениями, но и иными оракторами.

\title{
КАючевые слова
}

социально-психологическая аАаптация, Аезадаптация, нервно-психическая устойчивость, стрессоустойчивость, конструктивные стратегии поведения, психологическое зАоровье, преололение, совладание, копинг, ресурсы

\section{Основные положения}

- социально-психологическая адаптация - целостный системный процесс, сопровожАающий взаимодействие человека со средой, оАним из базовых элементов успешности которого являются конструктивные стратегии совлаАания с трудными ситуациями;

- лица с выраженной конструктивностью поведения и развитой стрессоустойчивостью отАичаются высоким Уровнем аАаптивности, а Аица с низким и среАним уровнями конструктивности поведения, также как и лица с низкой стрессоустойчивостью, характеризуются сниженными аАаптационными возможностями;

- вылеляется еАиный фрактор психологического зАоровья мичности, в который с высокими корреляционными показателями входят компоненты стрессоустойчивости, аАаптивности, принятия Аругих и конструктивности повеАения совлаАания.

\section{Для цитирования}

Безуглова А. А., Васильева О.С., Правдина Л.Р. Особенности социально-психологической адаптации у лиц с разными стратегиями совладающего поведения // Российский психологический журнал. - 2017. - Т. 14, № 4. - С. 180-204.

Материалы статьи получены 03.04.2017

UDC 159.923

DOI: $10.21702 /$ rpj.2017.4.9

\section{Socio-Psychological Adaptation in Individuals with Different Coping Strategies}

\author{
Anna A. Bezuglova, Ol'ga S. Vasil'eva, Lida R. Pravdina* \\ Southern Federal University, Rostov-on-Don, Russian Federation \\ * Correspondence author. E-mail: Iprlis7@gmail.com
}

\begin{abstract}
Introduction. Psychological adaptation and behaviour strategies are system characteristics of the individual making him/her effective and able to work. The
\end{abstract}


paper deals with coping as a way of effective adaptation to various situations. The present study introduces a comparison of socio-psychological adaptation in groups with different indices of constructive behaviour.

Methods. Adaptation characteristics in individuals with different coping strategies were measured using (a) the socio-psychological adaptation technique by K. Rogers and R. Diamond, (b) the Prognoz-2 Questionnaire for Mental Stability Assessment by V. YU. Rybnikov, (c) and the Strategic Approach to Coping Scale (SACS) developed by S. Hobfoll (adapted by N.E. Vodop'yanova and E.S. Starchenkova). The study involved 51 production enterprise employees.

Results. A consistent analysis of differences took place in the sample groups with different constructiveness indices. The study results showed (a) no high stability among the respondents, (b) predominance of high scores of constructive behaviour among women, (c) predominance of low scores of constructive behaviour among men, (d) the relationship among high scores of constructive behaviour, a higher adaptation level, and high mental stability. The study revealed a factor for psychological health resources, which included: (a) the index of constructive behaviour, (b) adaptation and adaptability, (c) acceptance of others and stress tolerance.

Discussion. The findings confirm the results in other studies of the relationship among adaptation, stress tolerance, and constructive strategies of behaviour. The factor for psychological health resources demonstrates the statistical dependence of the relationship among positive factors of psychological health. A low general level of adaptation, mental tolerance, and also constructive behaviour among the respondents suggests that socio-psychological adaptation is determined not only by the feelings of satisfaction with life, work, and family relations, but also other factors.

\section{Keywords}

socio-psychological adaptation, disadaptation, mental stability, stress tolerance, constructive strategies of behaviour, psychological health, overcoming, coping, resources

\section{Highlights}

- Socio-psychological adaptation is an integral system process which accompanies human interaction with the environment; constructive strategies of coping with difficult situations are its basic elements.

- Individuals with a prominent constructive behaviour and stress tolerance have a high level of adaptability; individuals with low and medium levels of constructive behaviour, and also individuals with a low stress tolerance level have lower adaptation ability.

- A unified factor for psychological health includes high correlation indices of the following components: stress tolerance, adaptability, acceptance of others, and constructive coping behaviour. 


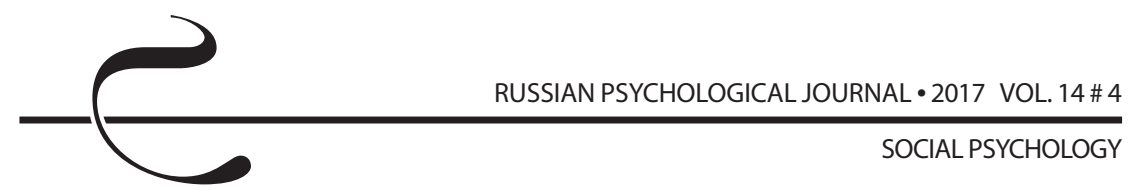

\section{For citation}

Bezuglova A. A., Vasil'eva O. S., Pravdina L. R. Socio-Psychological Adaptation in Individuals with Different Coping Strategies. Rossiiskii psikhologicheskii zhurnal - Russian Psychological Journal, 2017, V. 14, no. 4, pp. 180-204 (in Russian).

Original manuscript received 03.04.2017

\section{Введение}

В условиях современной действительности одной из важнейших составляющих благополучия личности становится способность к быстрой и эффективной социально-психологической адаптации. В настоящее время состояние российского общества, с одной стороны, характеризуется расширением возможностей людей, а с другой - проявлениями системного кризиса, охватившего большинство сфер экономической, социальной, культурной и духовной жизни нашего общества. В итоге у многих растет общая неуверенность в завтрашнем дне, а жизненная ситуация оценивается как наполненная стресс-факторами, что, безусловно, отражается на самочувствии, настроении, состоянии личностных адаптационных ресурсов членов нашего общества. В то же время, общество всегда заинтересовано в существовании жизнеспособных людей, выражающих себя конструктивно в любых условиях, поэтому для нас представляет исследовательский интерес изучение системных связей адаптивных возможностей личности с ее стратегиями совладающего поведения.

В связи с этим вопросы социально-психологической адаптации, стрессоустойчивости и конструктивности поведения не перестают быть актуальными; более того, профессиональным долгом психологов является их мониторирование у различных групп населения. Как утверждает Н.Е. Водопьянова, «интенсивное изучение факторов, способствующих успешной профессиональной адаптации, выступает одним из доминирующих направлений прикладных психологических исследований» [1, с. 73].

При проведении исследования мы опирались на следующие представления, положения и выявленные закономерности: 1) представления о социальнопсихологической адаптации и личностном адаптационном потенциале, развиваемые в работах R. S. Lazarus и S. Folkman [2], К.А. Абульхановой-Славской [3], Л.И. Анцыферовой [4], А.А. Налчаджян [5] и А. А. Реана [6], А. А. Куприна [7], И. А. Красильникова и В.В. Константинова [8], А.Г. Маклакова [9]; 2) работы по исследованию стрессоустойчивости, эмоциональной устойчивости Л.Г. Дикой [10]; 3) работы Т.Л. Крюковой [11], С. К. Нартовой-Бочавер [12] по проблемам преодолевающего поведения и мотивации совладающего поведения; работы В. А. Бодрова [13], С. А. Шапкина [14] по механизмам преодоления трудностей. 
Обобщая современный уровень развития социально-психологических концепций адаптации, И. А. Красильников и В.В. Константинов пишут, что «адаптация - это целостный, системный процесс, характеризующий взаимодействие человека с природной и социальной средой; особенности процесса адаптации определяются психологическими свойствами человека, уровнем его личностного развития, характеризующегося совершенством механизмов личностной регуляции поведения и деятельности; критериями адаптированности можно считать не только выживаемость человека и нахождение места в социальной структуре, но и общий уровень психологического здоровья, способность развиваться в соответствии со своим жизненным потенциалом, субъективное чувство самоуважения и осмысленность жизни» [8, с. 937].

С.А. Шапкин и Л.Г. Дикая представляют адаптацию как процесс формирования стратегий совладания с трудной ситуацией с задействованием разных уровней регуляции, в котором системообразующим фактором адаптации являются мотивационно-волевые стратегии. Эти стратегии как раз и определяют силу и направленность процессов обеспечения деятельности - энергетических, эмоциональных и когнитивных [14]. А.А. Куприн отмечает, что социально-психологическую адаптацию можно рассматривать и как процесс, и как состояние, являющееся итогом взаимодействия субъекта адаптации с внешней средой [7]. И. А. Красильников и В. В. Константинов указывают на существование таких видов адаптации, как профессиональная, социальноэкономическая, экономико-психологическая, социально-психологическая [8].

Успешность социально-психологической адаптации личности и сопряженных с ней внутриличностных конфликтов определяется способностью осуществлять конструктивные стратегии поведения в затрудненных и трудных жизненных ситуациях. А. А. Налчаджян описывает следующие признаки дезадаптированной личности: переживание ею длительных внутренних и внешних конфликтов без нахождения психических механизмов и форм поведения, необходимых для их развития [5]. Косвенно социально-психологическая адаптация отражается в состоянии субъективного благополучия, о чем упоминает Р.М. Шамионов [15], связывая субъективное благополучие с адаптацией, выделяя в нем регулятивную (адаптивную) функцию, участвующую в регуляции самоотношения, самочувствия и отношений с окружающими.

Важнейшим компонентом, лежащим в основе процессов успешной адаптации, является стрессоустойчивость - фактор, позволяющий личности противостоять стрессам. В.А. Бодров [13] отмечает, что в настоящее время большинство авторов в качестве синонима стрессоустойчивости употребляет термин «эмоциональная устойчивость», механизмы и сущность которой изучены лучше. Стрессоустойчивость есть свойство личности, способствующее высокой продуктивности деятельности в экстремальном пространстве. 


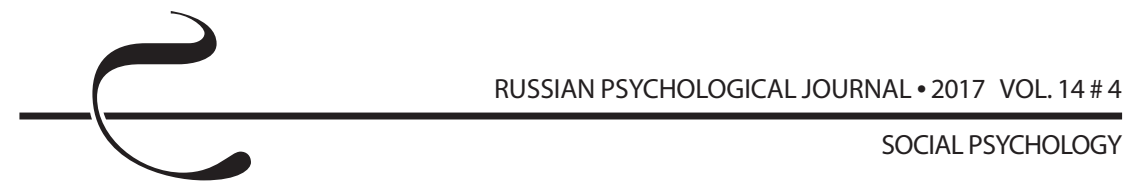

Сегодня термин «стрессоустойчивость» объединяет такие частные составляющие, как эмоциональная устойчивость, психологическая устойчивость к стрессу, стресс-резистентность, фрустрационная толерантность, - подобное смешение понятий является достаточно распространенным явлением для многих авторов [16].

При нормально протекающей социально-психологической адаптации формируется свойство адаптивности (наличие множества разноуровневых ресурсов), которое субъективно переживается как состояние благополучия. Ему угрожает стресс, поэтому личность формирует особый комплекс различных способностей, называемый стрессоустойчивостью. Одним из важнейших элементов стрессоустойчивости является владение личностью поведенческими стратегиями, позволяющими успешно преодолевать стресс, снижающими риск возникновения дезадаптации или полностью адаптирующими личность. Еще R.S. Lazarus и S. Folkman связывали адаптированность с отсутствием переживания угрозы, выделяя в адаптационном процессе две стратегии совладающего поведения: а) проблемно-ориентированное поведение; б) поведение, ориентированное на изменение собственных установок в отношении к ситуации [2]. Среди российских психологов Л.И. Анцыферова, опираясь на работы H. Thomae, рассматривает процессы адаптации в контексте преодоления личностью трудной жизненной ситуации [4]. И.А. Красильников и В.В. Константинов полагают, что процесс преодоления проблемных ситуаций можно считать процессом социально-психической адаптации личности, в ходе которого открываются новые способы поведения, новые программы и планы внутриличностных процессов [8]. И.Г. Малкина-Пых отмечает, что совладающее поведение реализуется посредством применения разных копинг-стратегий на основе ресурсов личности и среды [17]. Ю.В. Обухова указывает, что особенности совладающего поведения студентов различных направлений подготовки сказываются на их Я-концепции [18].

Сам термин «преодолевающее поведение» («сорing behavior») происходит от английского «соре» - преодолевать; на русский язык его переводят как адаптивное, совладающее поведение, или психологическое преодоление; он включает все виды взаимодействия субъекта с задачами внешнего или внутреннего характера. Современные исследователи выделяют большое разнообразие способов совладания с трудными ситуациями, или copingмеханизмов, начиная от механизмов психологической защиты и индивидуальных реакций до жизненных стратегий, однако исчерпывающе решить проблему определения единого признака успешного coping-поведения как критерия психологической адаптации личности в настоящее время пока не удается. Таким образом, копинг-поведение, преодолевающее, совладающее поведение - это деятельность личности по поддержанию или сохранению 
баланса между требованиями среды и ресурсами, удовлетворяющими эти требования. Оно лучше адаптирует человека в ситуации, помогая ему овладеть ею, ослабить или смягчить ее требования, поддержать его благополучие, физическое и психическое здоровье и удовлетворенность социальными отношениями. Поведение преодоления инициируется ситуацией, в которой человек ощущает стресс, и завершается, когда ситуация для субъекта утрачивает свою значимость.

При изучении эффективности преодоления выявляется его связь с психическим благополучием, т. к. основным критерием эффективности становится снижение уровня невротизации, которое можно оценить по уменьшению проявлений депрессии, тревожности, раздражительности и психосоматических симптомов, ослаблению чувства «уязвимости» К стрессам. Эффективными стратегиями преодоления считаются преобразование ситуации или ее переосмысление, наименее эффективными - избегание и самообвинение [19]. Эффективность защитных форм преодоления оценивается неоднозначно: например, искаженное понимание ситуации N. Haan [20] считает дезадаптивным, а P. Becker [21] уверен, что за счет такого поведения достигается ослабление воспринимаемого стресса, позволяющее субъекту лучше мобилизовать энергию для активного преодоления сложностей. Также неоднозначно оцениваются эмоционально-экспрессивные формы копинга. С одной стороны, выражение чувств считается конструктивным способом преодоления стресса, а с другой, по данным психосоматических исследований, сдерживание негативных чувств является фактором риска нарушения психологического здоровья человека [19].

На выбор той или иной формы противостояния жизненным трудностям влияет принадлежность человека к определенной социальной группе, его социальный опыт и полоролевые стереотипы. Так, женщины, в основном, склонны к эмоциональному совладанию и психологическим защитам, а мужчины предпочитают путь преобразования внешней ситуации [22]. Сопоставляя поведение студентов-афроамериканцев и белых американских студентов в условиях учебных стрессов, J. Jung и H. Khalsa [23] показали, что студенты-афроамериканцы чаще ожидают их наступление, выбирают активные действия в трудных ситуациях, рассчитывая при этом на поддержку семьи. Для белых студентов характерна ориентация на поддержку друзей, и их копинг, в целом, менее эффективен. D. Shek [24] на примере работающих мужчин и женщин в Китае показал, что в различных сферах отношений при стрессах для женщин характерен поиск социальной поддержки, а для мужчин - попытки устранить неприятную ситуацию. В исследовании наиболее распространенных объектов конфликтного поведения М. Jerusalem и R. Schwarzer [25] обнаружили, что выбор стратегии преодоления конфликта 


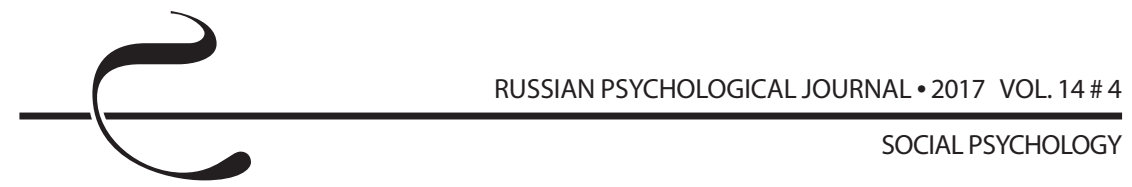

зависит от статуса оппонента. E. Wells-Parker [26] показал ролевую специфику преодоления трудных ситуаций повседневности у женщин в контексте их четырех основных ролей: профессионала, жены, матери и управляющего финансами. Женские стратегии оказались более активными, инструментальными в семье, что показывает обусловленность копинг-стратегии историческим (при разделении на традиционно мужские и женские сферы занятий) или социальным опытом. Таким образом, предпочтение стратегий преодоления отчасти детерминировано достаточно глубокими культурно-историческими корнями, гендерными и социальными стереотипами.

Сегодня авторы наиболее адаптивными (конструктивными) копингстратегиями считают те, которые направлены на разрешение проблемной ситуации (активные действия по устранению источника стресса, планирование своих действий в отношении проблемной ситуации, поиск помощи или совета у своего социального окружения, признание реальности ситуации и т. д.). Дезадаптивными (неконструктивными) являются стратегии, связанные с эмоциональным реагированием в проблемной ситуации, отрицанием стрессовой ситуации или отказом от разрешения проблемы [17].

Таким образом, стратегии совладания являются важным адаптационным ресурсом личности, и от степени их конструктивности зависят успешность преодоления стрессов, сохранение здоровья субъекта общения и труда [5]. Работы по исследованию связи социально-психологической адаптации с поведением в трудных жизненных ситуаций единичны. Адаптацию непосредственно в связи с копинг-стратегиями изучали Н.Е. Водопьянова [27], Н. А. Шмакова [28] и И. В. Малышев [29]. В этих работах представлено, что специалисты с высокими показателями личностного адаптационного потенциала чаще используют конструктивные модели преодолевающего поведения, обладают более высоким уровнем нервно-психической устойчивости и удовлетворенности качеством жизни, а также что уровень социально-психологической адаптации респондентов отчасти зависит от межкультурных, возрастных и гендерных особенностей.

В то же время респондентами в проведенных исследованиях являются менеджеры, студенты, специалисты, работающие в офисах, а для работников производственной сферы подобных исследований не проводилось.

\section{Методы}

Цель работы - исследование особенностей социально-психологической адаптации у лиц с разной выраженностью стратегий совладания. Основная выборка исследования была представлена сотрудниками $\mathrm{OOO}$ «N-металлобаза» (всего 51 человек, из них 34 мужчины и 17 женщин в возрасте от 25 до 50 лет, различных специальностей: менеджеры, водители, 
бухгалтеры и помощники бухгалтеров, кладовщики, грузчики, крановщики).

Общая гипотеза исследования: выраженность адаптации и стрессоустойчивость личности взаимосвязаны с особенностями ее стратегий совладающего поведения.

Частные гипотезы: 1) особенности социально-психологической адаптации и стрессоустойчивость взаимосвязаны с конструктивностью/ неконструктивностью совладающего поведения личности; 2) статистически можно выделить психологические детерминанты, объединяющие стрессоустойчивость, социально-психологическую адаптацию и особенности совладающего поведения.

Методики исследования: методика социально-психологической адаптации К. Роджерса и Р. Даймонда, методика «Анкета оценки нервно-психической устойчивости "Прогноз-2"» В.Ю. Рыбникова, методика «Шкала SACS C. Хобфолла» в адаптации Н.Е. Водопьяновой и Е.С. Старченковой. Достоверность полученных результатов обеспечена расчетом необходимых статистических показателей и критериев с использованием статистической системы SPSS-17 для Windows.

\section{Результаты}

Независимая переменная нашего исследования - стратегии совладающего поведения (измеренные по методике SACS). Интегральной характеристикой индивидуального паттерна этих стратегий, на наш взгляд, может служить обобщенный показатель для 6-ти шкал методики SACS - индекс конструктивности, который рассчитывается как частное для сумм шкал «ассертивные действия», «вступление в социальный контакт» и «поиск социальной поддержки», с одной стороны, и «избегание», «асоциальные действия» и «агрессивные действия» - с другой стороны. Как указывает Н.Е. Водопьянова, «значения индекса конструктивности до 0,85 свидетельствуют о низкой конструктивности, интервал 0,86-1,1 - о средней конструктивности, выше 1,1 - о высокой конструктивности» $[27$, с. 259].

Для полного обоснования выбора индекса конструктивности в качестве независимой переменной нами был произведен анализ корреляционных связей по r-критерию Пирсона внутри методики SACS, включая интегративный показатель «индекс конструктивности». Оказалось, в методике SACS больше всего связей имеет именно индекс конструктивности (прямые связи для «ассертивных действий», «вступления в социальный контакт», «поиска социальной поддержки», «осторожных действий»; обратные - для «избегания», «асоциальных действий», «агрессивных» и «манипулятивных» действий). Неохваченным индексом конструктивности оказался только показатель «импульсивные действия». Далее с помощью частотного анализа 
мы исследовали представленность в выборке лиц с различным индексом конструктивности (см. таблицу 1).

Таблица 1. Процентная представленность ^иц с различной выраженностью инАекса конструктивности (к соответствующим выборкам)

Table 1. Percentage of the individuals with different constructiveness indices (in relevant samples)

\begin{tabular}{|c|c|c|}
\hline $\begin{array}{c}\text { Выраженность индекса } \\
\text { конструктивности } \\
\text { Constructiveness index }\end{array}$ & $\begin{array}{l}\text { Выборка } \\
\text { Sample }\end{array}$ & $\begin{array}{l}\text { Процентная преАстав- } \\
\text { ^енность ^иц Аля соот- } \\
\text { ветствующей выборки } \\
\text { Percentage of the } \\
\text { individuals in the relevant } \\
\text { sample }\end{array}$ \\
\hline \multirow{3}{*}{$\begin{array}{l}\text { Высокая выражен- } \\
\text { ность индекса } \\
\text { конструктивности } \\
\text { High constructiveness } \\
\text { index }\end{array}$} & $\begin{array}{l}\text { Мужчины } \\
\text { Men }\end{array}$ & 8,8 \\
\hline & $\begin{array}{l}\text { Женщины } \\
\text { Women }\end{array}$ & 23,5 \\
\hline & $\begin{array}{l}\text { Совокупная выборка } \\
\text { Total }\end{array}$ & 13,7 \\
\hline \multirow{3}{*}{$\begin{array}{l}\text { Средняя выражен- } \\
\text { ность индекса } \\
\text { конструктивности } \\
\text { Average constructiveness } \\
\text { index }\end{array}$} & $\begin{array}{l}\text { Мужчины } \\
\text { Men }\end{array}$ & 64,7 \\
\hline & $\begin{array}{l}\text { Женщины } \\
\text { Women }\end{array}$ & 64,7 \\
\hline & $\begin{array}{l}\text { Совокупная выборка } \\
\text { Total }\end{array}$ & 64,7 \\
\hline \multirow{3}{*}{$\begin{array}{l}\text { Низкая выраженность ин- } \\
\text { декса конструктивности } \\
\text { Low constructiveness index }\end{array}$} & $\begin{array}{l}\text { Мужчины } \\
\text { Men }\end{array}$ & 26,5 \\
\hline & $\begin{array}{l}\text { Женщины } \\
\text { Women }\end{array}$ & 11,8 \\
\hline & $\begin{array}{l}\text { Совокупная выборка } \\
\text { Total }\end{array}$ & 21,6 \\
\hline
\end{tabular}

У мужчин и женщин численность в процентном отношении лиц со средней выраженностью индекса конструктивности одинакова, но среди женщин по сравнению с мужчинами почти на $15 \%$ больше лиц с высокой конструктивностью, а среди мужчин - на столько же больше лиц с низкой конструктивностью. В выборке около $65 \%$ респондентов имеет баланс конструктивных и неконструктивных стратегий, 14\% - конструктивных и $22 \%$ неконструктивных, однако показатели «ухудшают» мужчины (рисунок 1). 


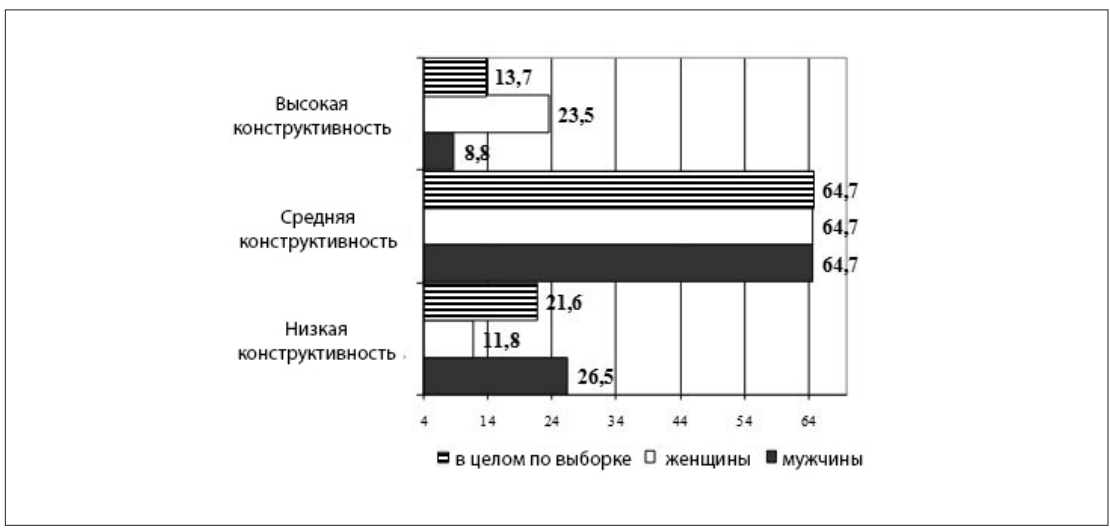

Рисунок 1. Процентное соотношение лиц мужской, женской и совокупных выборок с различной выраженностью индекса конструктивности

Figure 1. Percentage of male, female, and total samples with different constructiveness indices

Для исследования показателей социально-психологической адаптации у лиц с разной выраженностью индекса конструктивности использовался U-критерий Манна - Уитни (см. таблицу 2).

При сравнении групп с высоким и средним индексами конструктивности выявлены значимые различия в следующих частных показателях методики Роджерса - Даймонда: адаптивности, принятия других, эмоционального комфорта, эмоционального дискомфорта. Также можно говорить о тенденции различий в показателе «ведомость» в сравниваемых выборках.

При сравнении групп с высоким и низким индексами конструктивности выявлены значимые различия в частных показателях методики Роджерса Даймонда: адаптивности, дезадаптивности, принятия других, эмоционального комфорта и эмоционального дискомфорта.

При сравнении групп со средним и низким индексами конструктивности выявлены слабо выраженные различия в частных показателях методики Роджерса - Даймонда: адаптивности, дезадаптивности и непринятия себя, а также - тенденции слабых различий для показателя непринятия других. Из таблицы 3 видно, что лица с высокой конструктивностью преодолевающего поведения отличаются самым высоким уровнем адаптивности (самый низкий - у лиц с низкой конструктивностью), более высоким уровнем принятия других, более высоким уровнем эмоционального комфорта, меньшим, чем у остальных, эмоциональным дискомфортом и меньшей ведомостью. Лица с низкой конструктивностью совладающего поведения, помимо самой низкой 
адаптивности, отличаются более высокой дезадаптивностью, а также - более выраженным непринятием себя и других.

Таблица 2. Значимость различий Аля показателей алаптации (частные показатели метолики Роджерса - АаймонАа) у лиц с разным уровнем инАекса конструктивности (ИК)

Table 2. Differences for adaptation indices (particular indices by the RogersDiamond technique) in individuals with different constructiveness indices (Cl)

\begin{tabular}{|c|c|c|c|c|c|c|}
\hline \multirow{3}{*}{$\begin{array}{l}\text { Частные показатели мето- } \\
\text { Аики Роджерса - АаймонАа } \\
\text { Particular indices by the } \\
\text { Rogers-Diamond technique }\end{array}$} & \multicolumn{6}{|c|}{$\begin{array}{c}\text { Сравниваемые выборки и статистические по- } \\
\text { казатели Аля них } \\
\text { Compared samples with statistical indices }\end{array}$} \\
\hline & \multicolumn{2}{|c|}{$\begin{array}{l}\text { высокий - среА- } \\
\quad \text { ний ИК } \\
\text { High - Average (Cl) }\end{array}$} & \multicolumn{2}{|c|}{$\begin{array}{c}\text { высокий - } \\
\text { низкий ИК } \\
\text { High - Low (Cl) }\end{array}$} & \multicolumn{2}{|c|}{$\begin{array}{l}\text { среАний - низкий } \\
\text { ИК } \\
\text { Average - Low (Cl) }\end{array}$} \\
\hline & $U$ & $p$ & $U$ & $p$ & $U$ & $p$ \\
\hline $\begin{array}{l}\text { ААaптивность } \\
\text { Adaptability }\end{array}$ & 0,500 & 0,000 & 1,500 & 0,000 & 103,500 & 0,033 \\
\hline $\begin{array}{l}\text { Аезалаптивность } \\
\text { Disadaptability }\end{array}$ & 108,500 & 0,807 & 14,000 & 0,027 & 69,500 & 0,002 \\
\hline $\begin{array}{l}\text { Принятие себя } \\
\text { Self-acceptance }\end{array}$ & 107,500 & 0,781 & 30,000 & 0,479 & 155,000 & 0,487 \\
\hline $\begin{array}{l}\text { Непринятие себя } \\
\text { Self-rejection }\end{array}$ & 110,000 & 0,862 & 23,500 & 0,179 & 104,500 & 0,036 \\
\hline $\begin{array}{l}\text { Принятие Аругих } \\
\text { Acceptance of others }\end{array}$ & 32,000 & 0,002 & 8,500 & 0,004 & 170,000 & 0,769 \\
\hline $\begin{array}{l}\text { Непринятие Аругих } \\
\text { Rejection of others }\end{array}$ & 86,500 & 0,309 & 32,500 & 0,596 & 121,000 & 0,105 \\
\hline $\begin{array}{l}\text { Эмоциональный комооорт } \\
\text { Emotional comfort }\end{array}$ & 34,000 & 0,002 & 8,500 & 0,004 & 153,000 & 0,453 \\
\hline $\begin{array}{l}\text { Эмоциональный } \\
\text { Аискомдрорт } \\
\text { Emotional discomfort }\end{array}$ & 52,000 & 0,022 & 14,500 & 0,027 & 165,500 & 0,669 \\
\hline $\begin{array}{l}\text { Внутренний контроль } \\
\text { Internal control }\end{array}$ & 111,500 & 0,889 & 37,000 & 0,930 & 162,000 & 0,612 \\
\hline $\begin{array}{l}\text { Внешний контроль } \\
\text { External control }\end{array}$ & 110,500 & 0,862 & 33,500 & 0,659 & 155,000 & 0,487 \\
\hline $\begin{array}{l}\text { Аоминирование } \\
\text { Dominance }\end{array}$ & 98,500 & 0,553 & 29,500 & 0,425 & 162,000 & 0,612 \\
\hline $\begin{array}{l}\text { BeАOMOCTь } \\
\text { Following }\end{array}$ & 68,500 & 0,095 & 24,000 & 0,211 & 157,000 & 0,521 \\
\hline $\begin{array}{l}\text { Эскапизм } \\
\text { Escapism }\end{array}$ & 110,000 & 0,862 & 35,500 & 0,791 & 159,000 & 0,556 \\
\hline
\end{tabular}


СОЦИАЛЬНАЯ ПСИХОЛОГИЯ

Таблица 3. Значения внутригрупповых средних Аля частных показателей алаптации, обнаруживающих различия в выборках миц с разными уровнями индекса конструктивности

Table 3. Intragroup mean scores for particular adaptation indices in the samples of individuals with different constructiveness indices

\begin{tabular}{|c|c|c|c|c|c|c|}
\hline \multirow{3}{*}{$\begin{array}{c}\text { Частные пока- } \\
\text { затели методики } \\
\text { Роджерса - Ааймонаа } \\
\text { Particular indices by } \\
\text { the Rogers-Diamond } \\
\text { technique }\end{array}$} & \multicolumn{6}{|c|}{$\begin{array}{c}\text { Анализируемые выборки и статистические показа- } \\
\text { тели А^я них } \\
\text { Analyzed samples with statistical indices }\end{array}$} \\
\hline & \multicolumn{2}{|c|}{$\begin{array}{c}\text { Высокий индекс } \\
\text { конструктивности } \\
\text { High } \\
\text { constructiveness } \\
\text { index }\end{array}$} & \multicolumn{2}{|c|}{\begin{tabular}{|c|} 
Средний индекс \\
конструктив- \\
ности \\
Average \\
constructiveness \\
index
\end{tabular}} & \multicolumn{2}{|c|}{$\begin{array}{c}\text { Низкий инАекс } \\
\text { конструктив- } \\
\text { ности } \\
\text { Low } \\
\text { constructiveness } \\
\text { index }\end{array}$} \\
\hline & $M$ & $\sigma$ & $M$ & $\sigma$ & $M$ & $\sigma$ \\
\hline $\begin{array}{l}\text { ААаптивность } \\
\text { Adaptability }\end{array}$ & 139,3 & 11,3 & 122,8 & 5,6 & 115,9 & 10,0 \\
\hline $\begin{array}{l}\text { Аезалаптивность } \\
\text { Disadaptability }\end{array}$ & 117,4 & 17,8 & 121,6 & 8,9 & 132,1 & 7,7 \\
\hline $\begin{array}{l}\text { Непринятие себя } \\
\text { Self-rejection }\end{array}$ & 22,6 & 8,4 & 24,3 & 4,1 & 27,2 & 3,1 \\
\hline $\begin{array}{l}\text { Принятие Аругих } \\
\text { Acceptance of others }\end{array}$ & 26,0 & 2,2 & 21,1 & 4,3 & 20,6 & 4,3 \\
\hline $\begin{array}{l}\text { Непринятие Аругих } \\
\text { Rejection of others }\end{array}$ & 24,4 & 7,6 & 24,7 & 3,3 & 27,7 & 4,1 \\
\hline $\begin{array}{l}\text { Эмоциональный } \\
\text { коморорт } \\
\text { Emotional comfort }\end{array}$ & 31,7 & 3,2 & 26,3 & 4,8 & 25,1 & 4,3 \\
\hline $\begin{array}{l}\text { Эмоциональный } \\
\text { Аискомфрорт } \\
\text { Emotional discomfort }\end{array}$ & 22,0 & 4,2 & 26,4 & 3,8 & 27,2 & 4,6 \\
\hline $\begin{array}{l}\text { ВеАOMOCTь } \\
\text { Following }\end{array}$ & 20,4 & 4,2 & 22,8 & 3,3 & 23,3 & 3,5 \\
\hline
\end{tabular}

Мы отобразили графически внутригрупповые средние для частных показателей методики Роджерса - Даймонда, имеющих различия в выборках лиц с разными уровнями индекса конструктивности (см. рисунки 2 и 3). Из рисунков видно, что наибольшая адаптивность присуща лицам с высоким индексом конструктивности поведения. 


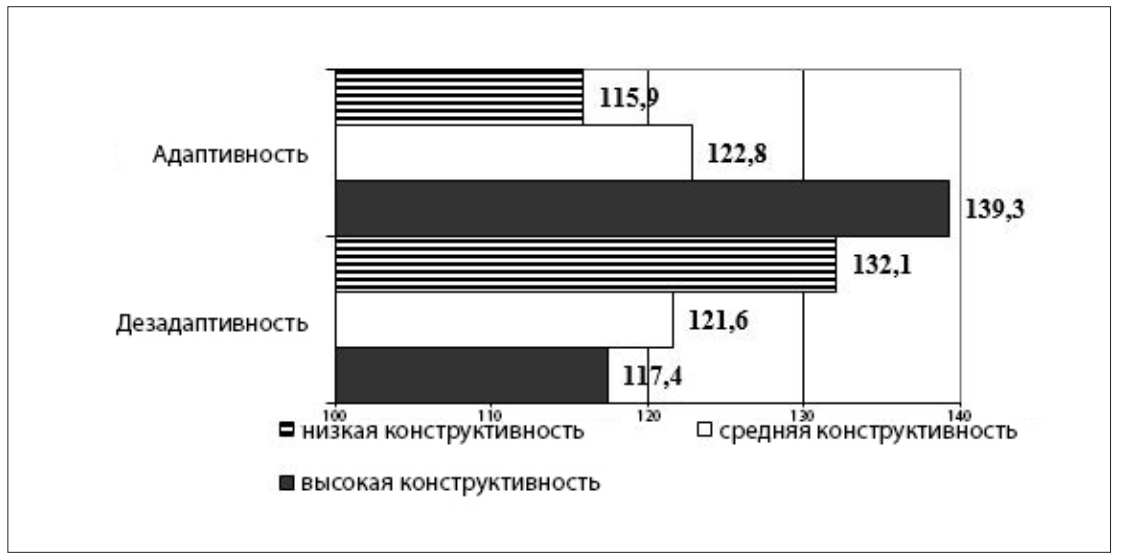

Рисунок 2. Показатели алаптивности/Аезадаптивности у лиц с различной выраженностью преололевающего поведения

Figure 2. Adaptability/disadaptability indices in individuals with different levels of coping behaviour

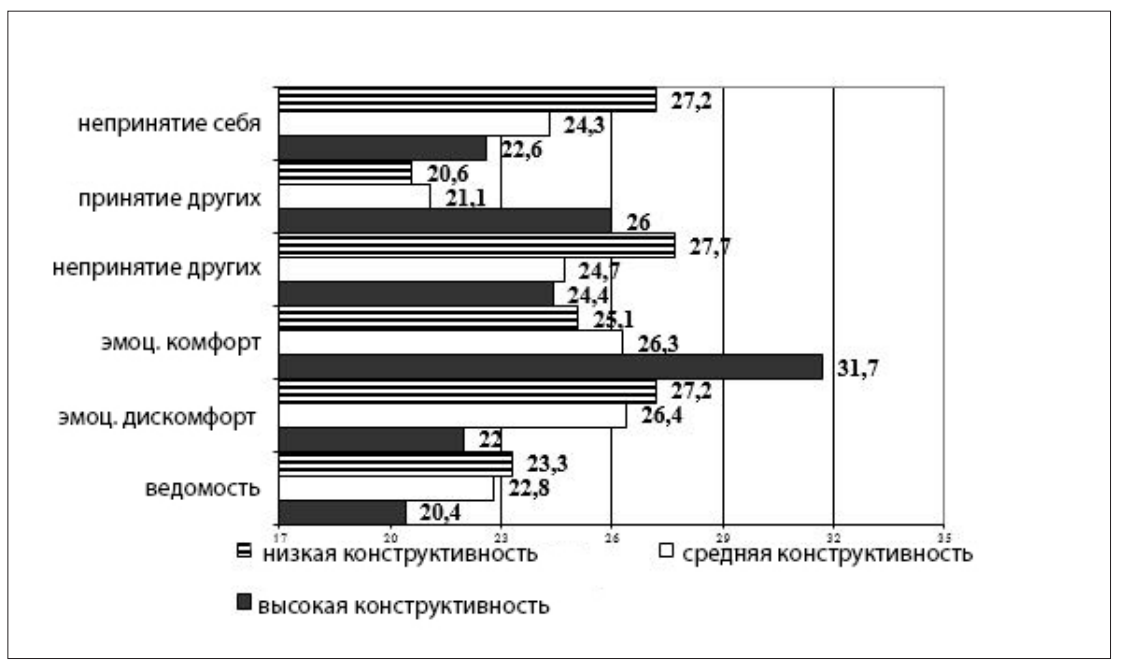

Рисунок 3. Выраженность частных показателей алаптации у миц с различной выраженностью индекса конструктивности преололевающего поведения

Figure 3. Particular adaptation indices in individuals with different constructiveness indices of coping behaviour 
Анализ различий средних в этих группах, проведенный с помощью критерия Манна - Уитни, подтвердил выявленные закономерности. Оказалось, что по большинству интегративных показателей социально-психологической адаптации лица с низким и средним индексами конструктивности близки. Отличительными особенностями лиц с низкой конструктивностью являются более низкая адаптация и меньшее самопринятие. Лица с высокой конструктивностью отличаются более высокой адаптацией, самопринятием, эмоциональной комфортностью и стремлением к доминированию.

Итак, особенности адаптации у лиц с высоким индексом конструктивности поведения заключаются в том, что у них более высокие частные показатели адаптивности, принятия других, эмоционального комфорта и более низкие частные показатели эмоционального дискомфорта и ведомости, а в отношении интегративных показателей - более высокая адаптация, более высокое принятие себя и других, более высокий уровень эмоциональной комфортности, большая интернальность. Особенности адаптации у лиц с низким индексом конструктивности поведения заключаются в том, что у них присутствуют низкая адаптивность, более высокая дезадаптивность, повышенные уровни непринятия себя и других, менее выражено самопринятие, и присутствует низкий уровень адаптации. При этом отмечается пониженный уровень адаптивных возможностей в целом для исследованной выборки, как у лиц с высокой конструктивностью поведения (в среднем $57 \%)$, так и у лиц с низкой конструктивностью (в среднем 48\%).

Для исследования особенностей стрессоустойчивости у лиц с разной выраженностью индекса конструктивности был произведен расчет U-критерия Манна - Уитни и величин внутригрупповых средних для показателя нервно-психической устойчивости выборок респондентов с высокой, средней и низкой выраженностью индекса конструктивности (см. таблицу 4).

Как видно из таблицы 4, во всех случаях имеются значимые различия для показателя НПУ попарно сравниваемых выборок респондентов с различной выраженностью индекса конструктивности, однако для сравниваемых выборок лиц со средней и низкой конструктивностью различия выражены слабее, хотя их внутригрупповые средние значимо отличаются. Это обусловлено достаточно высокими стандартными отклонениями в выборках, отражающими то, насколько отличаются реальные значения отдельных членов выборок от внутригрупповых средних (U-критерий как бы накладывает одну выборку на другую). Лица с высокой конструктивностью имеют высокий внутригрупповой уровень НПУ (стрессоустойчивости), а лица с низкой конструктивностью самые низкие значения НПУ.

Результаты расчета частот показателей НПУ для лиц каждой выборки представлены в таблице 5 . 
Таблица 4. Значимость различий показателя стрессоустойчивости (методика НПУ «Прогноз») А^я респондентов с различной выраженностью инАекса конструктивности

Table 4. Differences in stress tolerance indices (by the Prognoz-2 technique) for respondents with different constructiveness indices

\begin{tabular}{|c|c|c|}
\hline $\begin{array}{c}\text { Сравниваемые выборки / выборка } \\
\text { Compare samples / sample }\end{array}$ & $\begin{array}{l}\text { Статистика } \\
\text { Statistics }\end{array}$ & $\begin{array}{l}\text { Показатель } \\
\text { Index }\end{array}$ \\
\hline ВЫСОКИЙ - СРеАНИЙ ИНАеКС & $\mathrm{U}$ & 7,000 \\
\hline $\begin{array}{l}\text { Конструктивности } \\
\text { High - average constructiveness index }\end{array}$ & $\mathrm{p}$ & 0,000 \\
\hline ВЫСОКИЙ - НИЗКИЙ ИНАеКС & $\mathrm{U}$ & 0,000 \\
\hline $\begin{array}{l}\text { конструктивности } \\
\text { High - low constructiveness index }\end{array}$ & $\mathrm{p}$ & 0,000 \\
\hline СреАНИй - НИЗКИЙ ИНАеКС & $\mathrm{U}$ & 30,000 \\
\hline $\begin{array}{l}\text { Конструктивности } \\
\text { Average - low constructiveness index }\end{array}$ & $p$ & 0,000 \\
\hline Аица с высокой конструктивностью & M & 3,9 \\
\hline Individuals with high constructiveness & $\sigma$ & 0,4 \\
\hline Аица со среАней конструктивнОстью & $M$ & 2,4 \\
\hline $\begin{array}{l}\text { Individuals with average } \\
\text { constructiveness }\end{array}$ & $\sigma$ & 0,6 \\
\hline Аица с низкой конструктИвностью & M & 1,2 \\
\hline Individuals with low constructiveness & $\sigma$ & 0,4 \\
\hline
\end{tabular}

Таблица 5. Процентное соотношение лиц с разным уровнем НПУ (нервно-психической устойчивости) в связи с выраженностью индекса конструктивности

Table 5. Percentage of individuals with different levels of mental stability (MS) and the constructiveness index

\begin{tabular}{|c|c|c|c|c|}
\hline \multirow[t]{2}{*}{$\begin{array}{c}\text { НПУ } \\
\text { в сте- } \\
\text { нах } \\
\text { MS in } \\
\text { stens }\end{array}$} & \multirow[t]{2}{*}{$\begin{array}{c}\text { Комментарии по НПу } \\
\text { Comments by MS }\end{array}$} & \multicolumn{3}{|c|}{$\begin{array}{c}\text { Процентная преАставленность Аиц с различ- } \\
\text { ной конструктивностью } \\
\text { Percentage of individuals with different } \\
\text { constructiveness }\end{array}$} \\
\hline & & $\begin{array}{c}\text { Высокая } \\
\text { High }\end{array}$ & $\begin{array}{l}\text { Cреаняя } \\
\text { Average }\end{array}$ & $\begin{array}{c}\text { Низкая } \\
\text { Low }\end{array}$ \\
\hline 1 & \multirow{2}{*}{$\begin{array}{l}\text { Неуловлетворительная } \\
\text { НПу } \\
\text { Unsatisfactory MS }\end{array}$} & 0 & 6,1 & 81,8 \\
\hline 2 & & 0 & 51,5 & 18,2 \\
\hline 3 & \multirow{2}{*}{$\begin{array}{l}\text { УАОвлетворительная } \\
\text { НПУ } \\
\text { Satisfactory MS }\end{array}$} & 14,3 & 42,4 & 0 \\
\hline 4 & & 85,7 & 0 & 0 \\
\hline
\end{tabular}


Видно, что неудовлетворительного уровня НПУ в выборке лиц с высокой конструктивностью не обнаруживается, и вся эта выборка находится в диапазоне удовлетворительной НПУ. Что касается лиц с низкой конструктивностью, то вся их выборка находится в диапазоне неудовлетворительной НПУ. При этом $42 \%$ лиц со средней конструктивностью находится в диапазоне удовлетворительной НПУ, остальные - в диапазоне неудовлетворительной НПУ. Обращает на себя внимание, что подуровня «хорошая НПУ» (выше 6 стенов) не достигает ни один обследованный нами респондент. Таким образом, первая частная гипотеза подтверждена: могут быть выделены особенности адаптации и стрессоустойчивости в связи с конструктивностью/неконструктивностью преодолевающего поведения личности.

С целью выявления связей показателей субъективного благополучия, стрессоустойчивости и стратегии преодолевающего поведения, была проведена факторизация данных (без вращения). Для подтверждения возможности факторного анализа определялась нормальность распределения (критерий Колмогорова - Смирнова) показателей переменных, включенных в факторном анализе. Значение величины разности $d=0,277$ критерия Колмогорова Смирнова, $\mathrm{p}<0,01$. По результатам факторного анализа (таблица 6) нами было получено 9 факторов; только в факторе 1 показатели преодолевающего поведения, адаптации и стрессоустойчивости имеют значимые факторные нагрузки (в основном, сильные и средние). Процент дисперсии, объясняющей 9-факторное решение - 27,34\%.

Фактор 1 объединяет показатели адаптации, выраженной стрессоустойчивости, конструктивности и принятия других (показатели с наиболее сильной факторной нагрузкой) и назван нами фактором «ресурсов психологического здоровья» - РПЗ. Неконструктивные стратегии преодоления и показатели дезадаптации в этом факторе имеют отрицательные веса; т. е. с первыми они несовместимы. Изучение компонентов фактора РПЗ показывает, что стрессоустойчивость напрямую и сильно связана с конструктивными стратегиями преодолевающего поведения и позитивными параметрами адаптации. Вторая частная гипотеза исследования подтверждена: статистически можно выделить психологические детерминанты, объединяющие стрессоустойчивость, высокую адаптивность и особенности преодолевающего поведения.

\section{Обсуждение результатов}

Полученные в целом в работе результаты удовлетворяют нашу общую гипотезу, согласно которой выраженность адаптации и стрессоустойчивость личности взаимосвязаны с особенностями ее стратегий преодолевающего поведения. 
Таблица 6. Факторные связи стратегий преололевающего поведения, показателей адаптации и стрессоустойчивости

Table 6. Factorial relations among coping strategies, adaptation, and stress tolerance

\begin{tabular}{|c|c|}
\hline $\begin{array}{l}\text { Показате^и } \\
\text { Indices }\end{array}$ & $\begin{array}{c}\text { Факторная нагрузка } \\
\text { Factor loading }\end{array}$ \\
\hline \multicolumn{2}{|c|}{ Преололевающее поведение } \\
\hline \multicolumn{2}{|c|}{ Coping behaviour } \\
\hline $\begin{array}{l}\text { ИнАеКС конструктивности* } \\
\text { Constructiveness index* }\end{array}$ & 0,906 \\
\hline $\begin{array}{l}\text { Асоциальные Аействия } \\
\text { Asocial behaviour }\end{array}$ & $-0,619$ \\
\hline $\begin{array}{l}\text { Манипулятивные Аействия } \\
\text { Manipulative behaviour }\end{array}$ & $-0,600$ \\
\hline $\begin{array}{l}\text { Вступ^ение в социальный контакт } \\
\text { Making social contacts }\end{array}$ & 0,598 \\
\hline $\begin{array}{l}\text { Поиск социальной поААержки } \\
\text { Search for social support }\end{array}$ & 0,568 \\
\hline $\begin{array}{l}\text { Ассертивные Аействия } \\
\text { Assertive behaviour }\end{array}$ & 0,433 \\
\hline $\begin{array}{l}\text { Осторожные Аействия } \\
\text { Careful behaviour }\end{array}$ & 0,390 \\
\hline ААवптация & Adaptation \\
\hline $\begin{array}{l}\text { ААаптация } \\
\text { Adaptation }\end{array}$ & 0,945 \\
\hline $\begin{array}{l}\text { AАаптивность } \\
\text { Adaptability }\end{array}$ & 0,709 \\
\hline $\begin{array}{l}\text { Аезалаптивность } \\
\text { Disadaptability }\end{array}$ & $-0,761$ \\
\hline $\begin{array}{l}\text { Самопринятие } \\
\text { Self-acceptance }\end{array}$ & 0,600 \\
\hline $\begin{array}{l}\text { Непринятие себя } \\
\text { Self-rejection }\end{array}$ & $-0,562$ \\
\hline $\begin{array}{l}\text { Принятие Аругих } \\
\text { Acceptance of others }\end{array}$ & 0,706 \\
\hline $\begin{array}{l}\text { Принятие Аругих } \\
\text { Acceptance of others }\end{array}$ & 0,417 \\
\hline $\begin{array}{l}\text { Непринятие Аругих } \\
\text { Rejection of others }\end{array}$ & $-0,553$ \\
\hline $\begin{array}{l}\text { Эмоциональная комдрортность } \\
\text { Emotional wellbeing }\end{array}$ & 0,495 \\
\hline
\end{tabular}




\begin{tabular}{|c|c|}
\hline $\begin{array}{c}\text { Показатели } \\
\text { Indices }\end{array}$ & $\begin{array}{c}\text { Факторная нагрузка } \\
\text { Factor loading }\end{array}$ \\
\hline $\begin{array}{l}\text { Эмоциональный комфорт } \\
\text { Emotional comfort }\end{array}$ & 0,302 \\
\hline $\begin{array}{l}\text { Эмоциональный Аискомдрорт } \\
\text { Emotional discomfort }\end{array}$ & $-0,453$ \\
\hline $\begin{array}{l}\text { Интернальность } \\
\text { Internality }\end{array}$ & 0,406 \\
\hline $\begin{array}{l}\text { Внешний контроль } \\
\text { External control }\end{array}$ & $-0,340$ \\
\hline $\begin{array}{l}\text { Стремление к } А \text { оминированию } \\
\text { Desire to dominate }\end{array}$ & 0,343 \\
\hline \multicolumn{2}{|c|}{ Стрессоустойчивость } \\
\hline $\begin{array}{l}\text { Нервно-психическая устойчивость } \\
\text { Mental stability }\end{array}$ & 0,799 \\
\hline
\end{tabular}

Примечание: интегративные показатели (ИП) выделены курсивом и подчеркиванием. Note: integrative indices (II) are shown in italics and underlined.

Итоги исследования совпадают с результатами похожих по проблематике работ Н.А. Шмаковой [28] и Н.А. Краюшкиной [30], в частности, для выводов о взаимосвязи адаптации с конструктивным копингом и о различиях взаимосвязей адаптационных и копинговых характеристик у разных профессиональных, гендерных и возрастных групп. Однако в части преобладания конструктивных стратегий у женщин наши результаты противоречат данным Н.А. Шмаковой [28], указывающей, что менеджеры-мужчины используют активные и прямые стратегии, а менеджеры-женщины - просоциальные и непрямые. Это можно объяснить различиями в образовательном и культурном уровнях исследуемых выборок: описанные в нашем исследовании рабочие, видимо, отличаются более маргинальными личностными характеристиками, чем офисные менеджеры, ставшие респондентами Н.А. Шмаковой. Кроме того, из-за малого количества человек в выявленных группах с высокой и низкой конструктивностью поведения следует скорее говорить о возможной тенденции в существовании различий, чем о явной закономерности.

Обращает на себя внимание выявленный нами относительно общий низкий уровень адаптации, конструктивности и нервно-психической устойчивости у трудоустроенных людей. Это дает основание предполагать, что не только трудовая занятость населения обусловливает его уровень адаптивности и ставит вопросы о связи социально-психологической адаптивности 
с переживаниями удовлетворенности жизнью, трудом, удовлетворенностью семейными отношениями, с экзистенциальной исполненностью жизни и способами реализации свободного времени, что может представлять перспективу дальнейших исследований.

Проведенное эмпирическое исследование иллюстрирует системную связанность социально-психологической адаптации как со стрессоустойчивостью, так и со стратегиями преодолевающего поведения. Выявлены прямые связи позитивных предикторов адаптации с конструктивными стратегиями совладания. Из результатов работы следует, что ни путем проявления агрессивности, ни манипуляциями нельзя достичь достаточного уровня адаптации к социальной среде, самопонимания, принятия других, ресурсных уровней психологического здоровья. В то же время, повышая индекс конструктивности своего поведения, можно развивать свои адаптивные возможности и стрессоустойчивость.

Проведенное исследование позволило сделать следующие выводы:

1. В выборке преобладают респонденты со средней выраженностью конструктивного поведения преодоления и большинства показателей социально-психологической адаптации, а также с удовлетворительными показателями стрессоустойчивости (при полном отсутствии в выборке респондентов с высокой устойчивостью).

2. Мужская и женская подгруппы различаются по признаку использования конструктивных и низкоконструктивных стратегий преодоления: в женской выборке больше лиц с высококонструктивными стратегиями (преобладание ассертивности, вступления в социальный контакт и поиска социальной поддержки), а в мужской больше лиц с низкоконструктивными стратегиями (превалирование избегания, асоциальных и агрессивных действий).

3. Лица с высокой конструктивностью преодолевающего поведения отличаются самым высоким уровнем адаптивности (самый низкий - у лиц с низкой конструктивностью), более высоким уровнем принятия других, более высоким уровнем эмоционального комфорта, меньшим, чем у остальных, эмоциональным дискомфортом и меньшей ведомостью. Лица с низкой конструктивностью совладающего поведения, помимо самой низкой адаптивности, отличаются более высокой дезадаптивностью, а также - более выраженным непринятием себя и других.

4. По большинству интегративных показателей социально-психологической адаптации лица с низким и средним индексами конструктивности близки; их отличительными особенностями являются более низкая адаптация и меньшее самопринятие.

5. Лица с высокой конструктивностью поведения обладают удовлетворительным уровнем нервно-психической устойчивости; лица с низкой 
конструктивностью поведения характеризуются неудовлетворительной нервно-психической устойчивостью.

6. Выделен фактор ресурсов психологического здоровья, показывающий статистическую обусловленность взаимосвязи позитивных факторов социально-психологической адаптации, конструктивного поведения и стрессоустойчивости. В него вошли показатели с сильной факторной нагрузкой (индекс конструктивности поведения, адаптация и адаптивность, принятие других и стрессоустойчивость). Противоположными основным для этого фактора показателям (входят в него с отрицательным знаком) являются асоциальные действия, дезадаптивность и непринятие себя.

\section{Литература}

1. Водопьянова Н. Е., Капустина А. Н. Копинг-стратегии как фактор профессиональной адаптации // Вестник Ленинградского государственного университета им. А. С. Пушкина. - 2015. - Т. 5, № 1. - С. 73-85.

2. Lazarus R. S., Folkman S. Stress, appraisal, and coping. - N. Y. : Springer Publishing Company, 1984. - 218 p.

3. Абульханова-Славская К. А. Стратегия жизни. - М. : Мысль, 1991. - 299 с.

4. Анцыферова Л. И. Личность в трудных жизненных условиях: переосмысление, преобразование ситуаций и психологическая защита // Психологический журнал. - 1994. - Т. 15, № 1. - С. 3-15.

5. Налчаджян А. А. Социально-психическая адаптация личности: (Формы, механизмы и стратегии). - Ереван : Изд-во АН Армянской ССР, 1988. - 69 с.

6. Реан А. А., Кудашев А. Р., Баранов А. А. Психология адаптации личности : Учебно-научное издание. - СПб. : ПРАЙМ-ЕВРОЗНАК, 2006. - 479 с.

7. Куприн А. А. Специфика понимания адаптации в современной социальной психологии // Вестник Санкт-Петербургского университета МВД России. - 2009. - № 1. - С. 189-194.

8. Красильников И. А., Константинов В. В. Социально-психологическая адаптация личности и стратегии разрешения внутренних конфликтов // Известия Самарского научного центра РАН. - 2009. - № 4-4. - С. 937.

9. Маклаков А. Г. Личностный адаптивный потенциал: его мобилизация и прогнозирование в экстремальных условиях // Психологический журнал. - 2001. - Т. 22, № 1. - С. 16-24.

10. ДикаяЛ.Г.Итоги и перспективные направления исследований в психологии труда в XXI веке // Психологический журнал. - 2002. - Т. 23, № 6. - С. 18-37.

11. Крюкова Т. Л. Психология совладающего поведения: современное состояние, проблемы и перспективы // Вестник Костромского государственного университета. Серия: Педагогика. Психология. Социокинетика. - 2008. - № 4. - С. 147-153. 
12. Нартова-Бочавер С. К. «COPING BEHAVIOR» в системе понятий психологии личности // Психологический журнал. - 1997. - Т. 18, № 5. - С. 20-30.

13. Бодров В. А. Информационный стресс : Учебное пособие для вузов. - М. : Пер Сэ, 2000. - 352 c.

14. Шапкин С. А., Дикая Л. Г. Деятельность в особых условиях: компонентный анализ структуры и стратегий адаптации // Психологический журнал. 1996. - Т. 17, № 1. - С. 19-34.

15. Шамионов Р. М. Субъективное благополучие личности: психологическая картина и факторы. Монография. - Саратов : Научная книга, 2008. - 296 с.

16. Церковский А. Л. Современные взгляды на проблему стрессоустойчивости // Вестник Витебского государственного медицинского университета. - 2011. - Т. 10, № 1. - С. 6.

17. Малкина-Пых И. Г. Стратегии поведения при стрессе // Московский психологический журнал. - 2007. - № 12. - С. 15-25.

18. Обухова Ю. В. Особенности совладающего поведения студентов несоциономических специальностей в связи с особенностями их Я-концепции // Теоретические и практические аспекты психологии и педагогики : коллективная монография / под ред. И. В. Андулян. - Уфа : Аэтерна, 2015. - C. 138-155.

19. Nakano K. Coping strategies and psychological symptoms in a Japanese sample // Journal of Clinical Psychology. - 1991. - Vol. 47, № 3. - P. 346-350. DOI: 10.1002/1097-4679(199105)47:3<346::AID-JCLP2270470304>3.0.CO;2-H

20. Haan N. Coping and defense mechanisms related to personality inventories // Journal of Consulting Psychology. - 1965. - Vol. 29, № 4. - P. 373-378.

21. Becker P. Der Trierer Persoenlichkeitsfragebogen (TPF). Gottingen : Hogrefe, 1989. - $389 \mathrm{p}$.

22. Blanchard-Fields F., Sulsky L., Robinson-Whelen S. Moderating Effects of Age and Context on the Relationship Between Gender, Sex Role Differences, and Coping // Sex Roles. - 1991. - Vol. 25, Issue 11-12. - P. 645-660. - DOI: 10.1007/BF00289569

23. Jung J., Khalsa H. K. The Relationship of Daily Hassles, Social Support, and Coping to Depression in Black and White Students // Journal of General Psychology - 1989. - Vol. 116, Issue 4. - P. 407-417.

24. Shek D. T. L. Reliance On Self or Seeking Help From Others: Gender Differences in the Locus of Coping in Cinese Working Parents // The Journal of Psychology. - 1992. - Vol. 126, Issue 6. - P. 671-678.

25. Jerusalem M., Schwarzer R. Selbstkonzept und Ängstlichkeit als Einflußgrößen für Streßerleben und Bewältigungstendenzen // Zeitschrift für Entwicklungspsychologie und Pädagogische Psychologie. - 1989. - Vol. 21, № 4. P. 307-324. 
26. Wells-Parker E. et al. Development of Control-of-Outcome Scales and Self-Efficacy Scales for Women in Four Life Roles // Journal of Personality Assessment. - 1990. - Vol. 54, Issue 3-4. - P. 564-575. - DOI: 10.1080/00223891.1990.9674020

27. Водопьянова Н. Е. Психодиагностика стресса. - СПб. : Питер, 2009. - 336 с.

28. ШмаковаН.А. Взаимосвязь социально-психологической адаптации и копингстратегии у менеджеров // Вестник МГЛУ. - 2013. - № 16 (676). - С. 193-202.

29. Малышев И. В. Характеристика социально-психологической адаптации и копинг-стратегий личности в разных условиях социализации // Coвременные исследования социальных проблем. - 2012. - № 12. - С. 23.

30. Краюшкина Н.А. Социально-психологическая адаптация к менеджерской деятельности и копинг-стратегии у студентов в период прохождения практики // Вестник МГЛУ. - 2014. - № 16 (702). - С. 88-96.

\section{References}

1. Vodop'yanova N. E., Kapustina A. N. Coping strategies as a factor for professional adaptation. Vestnik Leningradskogo gosudarstvennogo universiteta im. A. S. Pushkina - Vestnik of Pushkin Leningrad State University, 2015, V. 5, no. 1, pp. 73-85 (in Russian).

2. Lazarus R. S., Folkman S. Stress, appraisal, and coping. N. Y., Springer Publishing Company, 1984. 218 p.

3. Abul'khanova-Slavskaya K. A. Strategiya zhizni [A life strategy]. Moscow, Mysl' Publ., 1991. 299 p.

4. Antsyferova L. I. An individual in difficult living conditions: rethinking, transformation of situations, and psychological defense. Psikhologicheskii zhurnal, 1994, V. 15, no. 1, pp. 3-15 (in Russian).

5. Nalchadzhyan A. A. Sotsial'no-psikhicheskaya adaptatsiya lichnosti: (Formy, mekhanizmy i strategii) [The person's socio-psychological adaptation: Forms, mechanisms, and strategies]. Yerevan, Academy of Sciences, Armenian SSR Publ., 1988. 69 p.

6. Rean A. A., Kudashev A. P., Baranov A. A. Psikhologiya adaptatsii lichnosti [The psychology of the person's adaptation]. St. Petersburg, PRAIM-EVROZNAK Publ., 2006. 479 p.

7. Kuprin A. A. Understanding adaptation in modern social psychology. Vestnik Sankt-Peterburgskogo universiteta MVD Rossii - Vestnik of the Saint-Petersburg University of the MIA of Russia, 2009, no. 1, pp. 189-194 (in Russian).

8. Krasil'nikov I. A., Konstantinov V. V. Socio-psychological adaptation of the individual and strategies for resolving internal conflicts. Izvestiya Samarskogo nauchnogo tsentra RAN - Izvestia of Samara Scientific Center of the Russian Academy of Sciences, 2009, no. 4-4, p. 937 (in Russian). 
9. Maklakov A. G. Personal adaptive potential: its mobilization, and forecasting in extreme conditions. Psikhologicheskii zhurnal, 2001, V. 22, no. 1, pp. 16-24 (in Russian).

10. Dikaya L. G. Results and promising directions in the psychology of labor in the 21 st century. Psikhologicheskii zhurnal, 2002, V. 23, no. 6, pp. 18-37 (in Russian).

11. Kryukova T. L. The psychology of coping behaviour: the current state, problems and prospects. Vestnik Kostromskogo gosudarstvennogo universiteta. Seriya: Pedagogika. Psikhologiya. Sotsiokinetika - Vestnik of Kostroma State University. Series: Pedagogy. Psychology, 2008, no. 4, pp. 147-153 (in Russian).

12. Nartova-Bochaver S. K. Coping behaviour in the conceptual system of personality psychology. Psikhologicheskii zhurnal, 1997, V. 18, no. 5, pp. 20-30 (in Russian).

13. Bodrov V. A. Informatsionnyi stress: Uchebnoe posobie dlya vuzov [Information stress]. Moscow, Per Se Publ., 2000. 352 p.

14. Shapkin S. A., Dikaya L. G. Activities in special conditions: A component analysis of the adaptation structure and strategies. Psikhologicheskii zhurnal, 1996, V. 17, no. 1, pp. 19-34 (in Russian).

15. Shamionov R. M. Sub"ektivnoe blagopoluchie lichnosti: psikhologicheskaya kartina ifaktory. Monografiya [Subjective well-being of the person: A psychological pattern and factors]. Saratov, Nauchnaya kniga Publ., 2008. 296 p.

16. Tserkovskii A. L. Modern views of stress tolerance. Vestnik Vitebskogo gosudarstvennogo meditsinskogo universiteta - Vestnik of Vitebsk State Medical University, 2011, V. 10, no. 1, p. 6 (in Russian).

17. Malkina-Pykh I. G. Strategies of stress behaviour. Moskovskii psikhologicheskii zhurnal - Moscow Psychological Journal, 2007, no. 12, pp. 15-25 (in Russian).

18. Obukhova Yu. V. Coping behaviour among students of non-socionomic profile and their self-concept. In: Andulyan I. V. (ed.). Teoreticheskie i prakticheskie aspekty psikhologii i pedagogiki: kollektivnaya monografiya [Theoretical and practical aspects of psychology and pedagogy]. Ufa, Aeterna Publ., 2015, pp. 138-155.

19. Nakano K. Coping strategies and psychological symptoms in a Japanese sample. Journal of Clinical Psychology, 1991, V. 47, no. 3, pp. 346-350. DOI: 10.1002/1097-4679(199105)47:3<346::AID-JCLP2270470304>3.0.CO;2-H

20. Haan N. Coping and defense mechanisms related to personality inventories. Journal of Consulting Psychology, 1965, V. 29, no. 4, pp. 373-378.

21. Becker P. Der Trierer Persoenlichkeitsfragebogen (TPF). Gottingen, Hogrefe, 1989. 389 p.

22. Blanchard-Fields F., Sulsky L., Robinson-Whelen S. Moderating effects of age and context on the relationship between gender, sex role differences, 
and coping. Sex Roles, 1991, V. 25, Issue 11-12, pp. 645-660. DOI: 10.1007/ BF00289569

23. Jung J., Khalsa H. K. The relationship of daily hassles, social support, and coping to depression in black and white students. Journal of General Psychology, 1989, V. 116, Issue 4, pp. 407-417.

24. Shek D. T. L. Reliance on self or seeking help from others: Gender differences in the locus of coping in Cinese working parents. The Journal of Psychology, 1992, V. 126, Issue 6, pp. 671-678.

25. Jerusalem M., Schwarzer R. Selbstkonzept und Ängstlichkeit als Einflußgrößen für Streßerleben und Bewältigungstendenzen. Zeitschrift für Entwicklungspsychologie und Pädagogische Psychologie, 1989, V. 21, no. 4, pp. 307-324.

26. Wells-Parker E. et al. Development of control-of-outcome scales and selfefficacy scales for women in four life roles. Journal of Personality Assessment, 1990, V. 54, Issue 3-4, pp. 564-575. DOI: 10.1080/00223891.1990.9674020

27. Vodop'yanova N. E. Psikhodiagnostika stressa [Psychodiagnostics of stress]. St. Petersburg, Piter Publ., 2009. 336 p.

28. Shmakova N. A. The relationship between socio-psychological adaptation and coping strategies in managers. Vestnik MGLU - Vestnik of Moscow State Linguistic University, 2013, no. 16 (676), pp. 193-202 (in Russian).

29. Malyshev I. V. Socio-psychological adaptation and coping strategies in various socialization conditions. Sovremennye issledovaniya sotsialnykh problem - Modern Research of Social Problems, 2012, no. 12, p. 23 (in Russian).

30. Krayushkina N. A. Socio-psychological adaptation of managerial activities and coping strategies in students during the internship period. Vestnik MGLU - Vestnik of Moscow State Linguistic University, 2014, no. 16 (702), pp. 88-96 (in Russian). 